\title{
The role of the oxidic support on the deactivation of Pt catalysts during the $\mathrm{CO}_{2}$ reforming of methane
}

\author{
J.H. Bitter, W. Hally, K. Seshan, J.G. van Ommen, J.A. Lercher * \\ Faculty of Chemical Technology, University of Twente, P.O. Box 217, 7500 AE Enschede, Netherlands
}

\begin{abstract}
Pt supported on $\gamma-\mathrm{Al}_{2} \mathrm{O}_{3}, \mathrm{TiO}_{2}$ and $\mathrm{ZrO}_{2}$ are active catalysts for the $\mathrm{CO}_{2}$ reforming of methane to synthesis gas. The stability of the catalysts increased in the order $\mathrm{Pt} / \gamma-\mathrm{Al}_{2} \mathrm{O}_{3}<\mathrm{Pt} / \mathrm{TiO}_{2}<\mathrm{Pt} / \mathrm{ZrO}_{2}$. For all catalysts, the decrease in activity with time on stream is caused by carbon formation, which blocks the active metal sites for reaction. With $\mathrm{Pt} / \mathrm{TiO}_{2}$ and $\mathrm{Pt} / \mathrm{ZrO}_{2}$, deactivation started immediately after the start of the reaction, while the $\mathrm{Pt} / \gamma-\mathrm{Al}_{2} \mathrm{O}_{3}$ catalyst showed an induction period during which carbon was accumulated without affecting the catalytic activity.
\end{abstract}

Keywords: Pt catalysts; Catalyst deactivation; $M e t h a n e / \mathrm{CO}_{2}$ reforming

\section{Introduction}

Methane $/ \mathrm{CO}_{2}$ reforming is an important route to produce $\mathrm{CO}$ rich synthesis gas or very pure carbon monoxide $[1,2]$. The highly endothermic reaction yields equimolar amounts of $\mathrm{CO}$ and hydrogen. Under usual reaction conditions the catalysts deactivate severely due to coke formation [3] via the exothermic $\mathrm{CO}$ disproportionation $\left(2 \mathrm{CO} \rightarrow \mathrm{C}+\mathrm{CO}_{2} ; \Delta H_{298 \mathrm{~K}}^{0}=\right.$ $-172.4 \mathrm{~kJ} / \mathrm{mol}$ ) and the moderately endothermic methane decomposition $\left(\mathrm{CH}_{4} \rightarrow \mathrm{C}+2 \mathrm{H}_{2}\right.$; $\Delta H_{298 \mathrm{~K}}^{0}=+74.9 \mathrm{~kJ} / \mathrm{mol}$ ). Reduction of the deactivation was achieved either by adding water or oxygen to the feed gas stream, i.e., to couple methane- $\mathrm{CO}_{2}$ reforming with methane steam reforming [4] or partial oxidation of $\mathrm{CH}_{4}$ [4]. Alternatively, the amount of coke may be

\footnotetext{
* Corresponding author. Fax. (+31-53) 4894683, e-mail j.a.lercher@ct.utwente.nl.
}

minimized by using catalysts which show a relatively slow rate of methane decomposition and/or $\mathrm{CO}$ disproportionation. In this respect, noble metal catalysts were reported to be promising [4-7].

We reported previously that $\mathrm{Pt}$ supported on $\mathrm{ZrO}_{2}$ is active, selective and stable for the $\mathrm{CO}_{2} / \mathrm{CH}_{4}$ reforming and that the extent of coke formation [8] was minimal. In order to test to what extent this is unique to $\mathrm{Pt} / \mathrm{ZrO}_{2}$, the catalytic properties of $\mathrm{Pt}$ catalysts supported on $\gamma-\mathrm{Al}_{2} \mathrm{O}_{3}, \mathrm{TiO}_{2}$ and $\mathrm{ZrO}_{2}$ are compared in the present study.

\section{Experimental}

\subsection{Catalyst preparation}

All catalysts were prepared by the incipient wetness technique. For this purpose, a solution 
of $\mathrm{H}_{2} \mathrm{PtCl}_{6} \cdot 6 \mathrm{H}_{2} \mathrm{O}$ in water $(0.01 \mathrm{~g} \mathrm{Pt}$ per $\mathrm{ml})$ was used. The support was first calcined for 15 $h$ at $1125 \mathrm{~K}$ (heating rate $3 \mathrm{~K} / \mathrm{min}$ ) in flowing air $(30 \mathrm{ml} / \mathrm{min}$ (NTP)). The support was isostatically pressed into pellets at 4000 bar for 5 min. The pellets were crushed and sieved to give grains having diameters between 0.3 and $0.6 \mathrm{~mm}$. The grains were impregnated with the $\mathrm{H}_{2} \mathrm{PtCl}_{6}$ solution to yield a catalyst with 0.5 wt.-\% Pt. The water was removed by heating the catalyst at $365 \mathrm{~K}$ for $2 \mathrm{~h}$ in a rotating evaporator followed by drying over night at 395 $\mathbf{K}$ in static air. Subsequently, the impregnated grains were calcined at $925 \mathrm{~K}$ for $15 \mathrm{~h}$ (heating rate $3 \mathrm{~K} / \mathrm{min}$ ). The $\mathrm{Pt}$ content of the catalyst was determined by atomic absorption spectroscopy. The following supports were used: $\gamma-\mathrm{Al}_{2} \mathrm{O}_{3}(000-3 \mathrm{AQ}, \mathrm{AKZO}), \mathrm{TiO}_{2}$ (P-25, Degussa, mixture of anatase and rutile) and $\mathrm{ZrO}_{2}$ (RC-100, Gimex, monoclinic).

\subsection{Catalyst testing}

Typically $500 \mathrm{mg}$ of catalyst were loaded into a tubular quartz reactor (inner diameter 5 $\mathrm{mm}$ ) which was placed in an oven. The catalyst grains were kept in place by quartz wool plugs. A thermocouple was placed on top of the catalyst bed to measure the catalyst temperature. The oven temperature was controlled by a Eurotherm temperature controller. The catalysts were reduced in situ with $5 \% \mathrm{H}_{2}$ in $\mathrm{N}_{2}$ for $1 \mathrm{~h}$ at $1125 \mathrm{~K}$. After reduction, the temperature was lowered in $\mathrm{Ar}$ to the reaction temperature (875 $\mathrm{K})$ and the catalyst was subsequently exposed to the feed gas mixture $\left(25 \% \mathrm{CH}_{4}, 25 \% \mathrm{CO}_{2}, 5 \%\right.$ $\mathrm{N}_{2}$ and $45 \%$ Ar for a total flow of $283 \mathrm{ml}$ $\left.\mathrm{min}^{-1}\right)$. The reaction products were analyzed in a gas chromatograph (Varian GC3300), equipped with two $3 \mathrm{~m}$ carbosieve columns and a TCD.

\subsection{Analysis of the carbon deposited on used catalysts}

The amount of carbon on used catalysts was determined by oxidation to $\mathrm{CO}_{2}$ using oxygen.
Prior to the analysis, the used sample (200 mg) was heated in $\mathrm{He}$ to $925 \mathrm{~K}$ (heating ramp 30 $\mathrm{K}, / \mathrm{min}$ ) to remove any adsorbed $\mathrm{CO}_{2}$. Subsequently, oxygen pulses $(525 \mu \mathrm{l})$ were added to the He stream. The oxygen content of the outlet was monitored with a mass spectrometer. Pulsing was continued until changes in the oxygen signal were no longer observed. The amount of carbon oxidized was calculated from the oxygen uptake.

\subsection{Dispersion measurements}

The dispersion of $\mathrm{Pt}$ was determined by pulse hydrogen chemisorption. The catalysts were reduced ex situ at $1125 \mathrm{~K}$. Subsequently, the catalysts were again reduced at $675 \mathrm{~K}$ in the pulse chemisorption apparatus. The samples were then flushed for $1 \mathrm{~h}$ in $\mathrm{Ar}$ at $675 \mathrm{~K}$ and cooled down to $273 \mathrm{~K}$. At this temperature, 52 $\mu \mathrm{l}$ pulses of $6 \% \mathrm{H}_{2} / \mathrm{Ar}$ were passed over the sample and the concentration of $\mathrm{H}_{2}$ at the reactor outlet was determined by a TCD. The dispersion was calculated from the extent of $\mathrm{H}_{2}$ uptake assuming a $\mathrm{Pt} / \mathrm{H}$ ratio of one.

\section{Results}

The physicochemical properties of the catalysts are summarized in Table 1 . The catalysts have similar metal dispersions.

Fig. 1 shows the activities of the different catalysts at $875 \mathrm{~K}$ as function of time on stream. The activities of the catalysts were initially similar. However, the $\mathrm{Pt} / \gamma-\mathrm{Al}_{2} \mathrm{O}_{3}$ deactivated almost completely within $10 \mathrm{~h}$. $\mathrm{Pt} / \mathrm{TiO}_{2}$ deacti-

Table 1

Physicochemical properties of the investigated Pt catalysts

\begin{tabular}{llll}
\hline Catalyst & $\begin{array}{l}\text { Metal loading } \\
\text { (wt. } \%)\end{array}$ & $\begin{array}{l}\text { BET surface area } \\
\left(\mathrm{m}^{2} \mathrm{~g}^{-1}\right)\end{array}$ & $\begin{array}{l}\text { Pt dispersion * } \\
(\%)\end{array}$ \\
\hline$\gamma-\mathrm{Al}_{2} \mathrm{O}_{3}$ & $0.5 \pm 0.2$ & 112 & 35 \\
$\mathrm{TiO}_{2}$ & $0.5 \pm 0.2$ & 5 & 25 \\
$\mathrm{ZrO}_{2}$ & $0.5 \pm 0.1$ & 16 & 33 \\
\hline
\end{tabular}




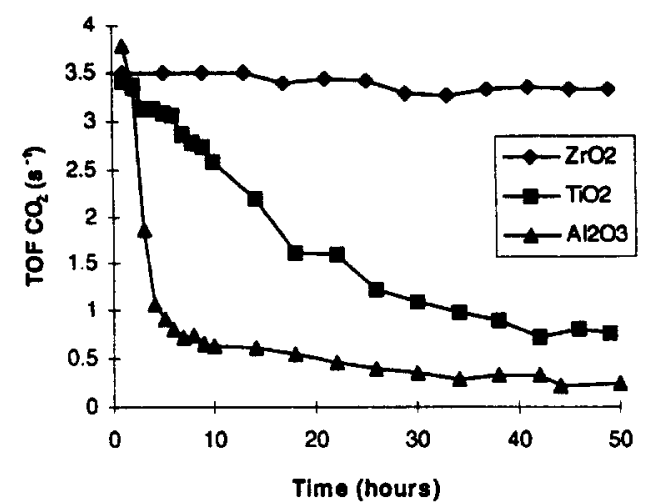

Fig. 1. Stability tests of different supported Pt catalysts for $\mathrm{CO}_{2} / \mathrm{CH}_{4}$ reforming at $875 \mathrm{~K}$.

vated with $80 \%$ within $50 \mathrm{~h}$ on stream whereas the $\mathrm{Pt} / \mathrm{ZrO}_{2}$ showed only a $5 \%$ deactivation within $50 \mathrm{~h}$ on stream.

After use at $875 \mathrm{~K}$ for $25 \mathrm{~h}$, the Pt dispersions of the different catalysts were again determined with and without the carbon removed from the surface by oxidation in $5 \% \mathrm{O}_{2} / \mathrm{He}$ at $675 \mathrm{~K}$. The results of these dispersion measurements are compiled in Table 2. The coked samples showed low hydrogen uptake values, while those of the oxidized and reduced samples (e.g., after carbon removal) were identical to those of the fresh samples.

Because the original dispersion was restored after burning the coke accumulated, we conclude that the dispersion of the catalyst is unaffected by use. Thus, we conclude that it is not the loss in metal dispersion that causes the deactivation during use, but the coverage of $\mathrm{Pt}$ by coke. In order to probe for the rate of coke

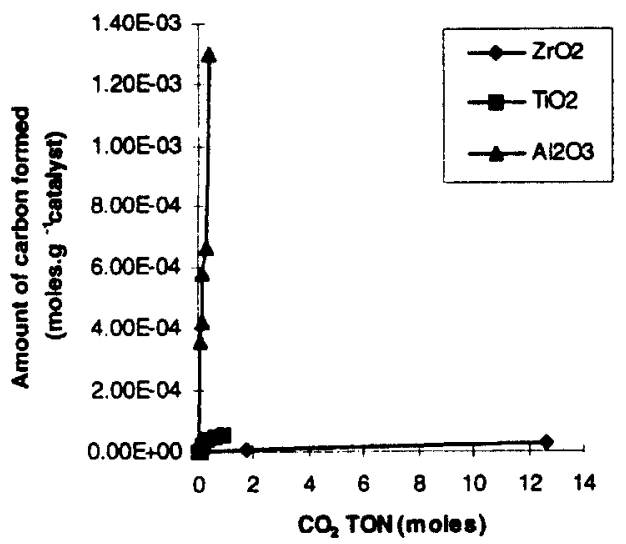

Fig. 2. Amounts of carbon formed as a function of the total amount of $\mathrm{CO}_{2}$ converted for different $\mathrm{Pt}$ catalysts during $\mathrm{CO}_{2} / \mathrm{CH}_{4}$ reforming at $875 \mathrm{~K}$.

formation in comparison to the rate of the reforming reaction, the reaction was stopped after various times on stream (i.e., after $0.5,1,2,5$, $10,25 \mathrm{~h}$ for $\mathrm{Pt} / \gamma-\mathrm{Al}_{2} \mathrm{O}_{3} ; 2,5,10,25,50 \mathrm{~h}$ for $\mathrm{Pt} / \mathrm{TiO}_{2}$ and $25,180 \mathrm{~h}$ for $\mathrm{Pt} / \mathrm{ZrO}_{2}$ ) and the amount of carbon was determined.

In Fig. 2, the amount of carbon deposited on the catalyst as function of the number of feed molecules converted (i.e., the turn over number, TON) is shown. The graph indicates that $\mathrm{Pt} / \gamma$ $\mathrm{Al}_{2} \mathrm{O}_{3}$ formed more coke than $\mathrm{Pt} / \mathrm{TiO}_{2}$ and $\mathrm{Pt} / \mathrm{ZrO}_{2}$. In Fig. 3, the reaction rates for the three catalysts (i.e, the number of molecules converted per accessible Pt site per s) are plotted versus the amount of carbon formed. The $\mathrm{Pt} / \gamma-\mathrm{Al}_{2} \mathrm{O}_{3}$ catalyst showed an induction period during which the catalyst maintained high activity despite the carbon accumulation. Subse-

Table 2

Dispersions of the different Pt catalysts, fresh, used and after regeneration

\begin{tabular}{llcc}
\hline Catalyst & Treatment & Apparent dispersion (\%) & $\mathrm{CO}_{2}$ conversion (\%) \\
\hline $\mathrm{Pt} / \gamma-\mathrm{Al}_{2} \mathrm{O}_{3}$ & Fresh catalyst & 35 & 32 \\
$\mathrm{Pt} / \gamma-\mathrm{Al}_{2} \mathrm{O}_{3}$ & Used at $875 \mathrm{~K}$ for $25 \mathrm{~h}$ & 9 & 3 \\
$\mathrm{Pt} / \gamma-\mathrm{Al}_{2} \mathrm{O}_{3}$ & Used at $875 \mathrm{~K}$ for $25 \mathrm{~h}$, after carbon burn off & 35 & 20 \\
$\mathrm{Pt} / \mathrm{TiO}_{2}$ & Fresh catalyst & 25 & 8 \\
$\mathrm{Pt} / \mathrm{TiO}_{2}$ & Used at $875 \mathrm{~K}$ for $25 \mathrm{~h}$ & 0.5 & 30 \\
$\mathrm{Pt} / \mathrm{TiO}_{2}$ & Used at $875 \mathrm{~K}$ for $25 \mathrm{~h}$, after carbon burn off & 25 & 29 \\
$\mathrm{Pt} / \mathrm{ZrO}_{2}$ & Fresh catalyst & 33 & 7 \\
$\mathrm{Pt} / \mathrm{ZrO}_{2}$ & Used at $875 \mathrm{~K}$ for $25 \mathrm{~h}$ & 32 & \\
$\mathrm{Pt} / \mathrm{ZrO}_{2}$ & Used at $875 \mathrm{~K}$ for $25 \mathrm{~h}$, after carbon burn off & 32 & \\
\hline
\end{tabular}




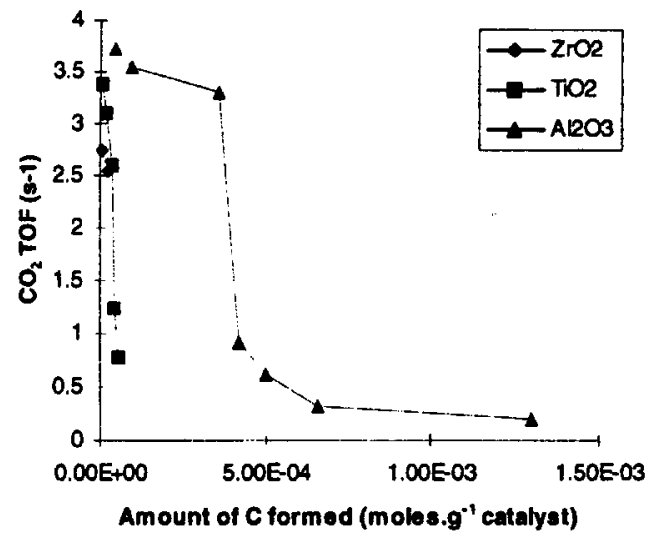

Fig. 3. Activity of Pt catalysts as a function of the amount of carbon formed during $\mathrm{CO}_{2} / \mathrm{CH}_{4}$ reforming at $875 \mathrm{~K}$.

quently, the catalyst deactivated quickly. $\mathrm{Pt} / \mathrm{TiO}_{2}$ and $\mathrm{Pt} / \mathrm{ZrO}_{2}$ did not show such an induction period.

\section{Discussion}

All three catalysts deactivated with time on stream. Because hydrogen chemisorption showed a marked decrease of the accessible metal surface area after use, the deactivation is concluded to be caused by blocking of a fraction of the metal surface or by sintering. The fact that the catalysts could be completely regenerated by means of oxidation suggests that it is primarily coke that blocks the metal surface. There was no indication of a change in the size of the metal crystallites.

The concentrations of coke formed on the three catalysts is very different after $25 \mathrm{~h}$ of reaction. $\mathrm{Pt} / \mathrm{ZrO}_{2}$ and $\mathrm{Pt} / \mathrm{TiO}_{2}$ showed low concentrations of coke, $7.7 \times 10^{-6}$ and $4.6 \times$ $10^{-5} \mathrm{~mol}$ carbon per $\mathrm{g}$ catalyst, respectively, while the concentration of coke deposited on the $\mathrm{Pt} / \gamma-\mathrm{Al}_{2} \mathrm{O}_{3}$ sample is significantly higher, i.e., $6.6 \times 10^{-4} \mathrm{~mol}$ carbon per $\mathrm{g}$ catalyst. The way the coke and the available metal surface change the rate of methane $/ \mathrm{CO}_{2}$ reforming during the experiments is quite different for the three tested catalysts. For $\mathrm{Pt} / \mathrm{ZrO}_{2}$ and $\mathrm{Pt} / \mathrm{TiO}_{2}$, the TOF strongly decreased with increasing amounts of carbon deposited while a more complex deacti- vation pattern was found for $\mathrm{Pt} / \gamma-\mathrm{Al}_{2} \mathrm{O}_{3}$. In the latter case, the initial build up of coke is not accompanied by a decrease in activity. However, after a certain period, the deactivation sets in and proceeds more rapidly compared to the other two samples. A separate experiment in which the $\gamma$-alumina carrier was exposed to the reaction gas mixture at $875 \mathrm{~K}$ for $25 \mathrm{~h}$ showed clearly that the amount of coke formed was nearly identical with that on $\mathrm{Pt} / \gamma-\mathrm{Al}_{2} \mathrm{O}_{3}$. This indicates that the coke is primarily formed on the carrier material. The reason for the different deactivation behavior for the Pt catalysts is then speculated to be related to the fact that the surface of the $\mathrm{Pt}$ crystallites of $\mathrm{Al}_{2} \mathrm{O}_{3}$ differs from that on partially reduced supports like $\mathrm{TiO}_{2}$. In both cases, coke formation is concluded to occur primarily on the support. The coke formed on the support covers, with time on stream, the metal particle. In the latter case of $\mathrm{Pt} / \mathrm{TiO}_{2}$, it is well established that small oxidic crystallites decorate the metal particles $[9,10]$ and may so allow the oxide catalyzed reaction to occur close to the metal, which in turns lets coking start immediately to affect adversely the reaction on the metal.

\section{Conclusions}

The results show that the activity of the catalysts for the methane $/ \mathrm{CO}_{2}$ reforming is determined by the availability of $\mathrm{Pt}$. The deactivation is primarily caused by coke deposition on the $\mathrm{Pt}$ crystals. The deactivation is concluded to originate from the catalyst support and the individual deactivation behavior depends subtly on the microstructural arrangement of the metal particle on the support.

\section{Acknowledgements}

This project was supported by an EU contract, Contract no. JOU2-CT92-0073 


\section{References}

[1] S. Teuner, Hydrocarbon Process., 64 (1985) 106.

[2] G. Kurz and S. Teuner, Erdöl Kohle, 43(5) (1990) 171.

[3] F. Fischer and H. Tropsch, Brennst.-Chem., 3 (1928) 36.

[4] A.T. Ashcroft, A.K. Cheetham, M.L.H Green and P.D.F. Vernon, Nature (London), 225 (1991) 352.

[5] N.R. Udengaard, J.B. Hansen, D.C. Hanson and J.A. Stal, Oil Gas J., (9 March 1992) 62.
[6] D.F. Vernon, M.L.H. Green, A.K. Cheetham and A.T. Ashcroft, Catal. Today, 13 (1992) 417.

[7] J.R. Rostrup-Nielsen and J-H. Bak Hansen, J. Catal., 144 (1993) 38.

[8] K. Seshan, H.W. ten Barge, W. Hally, A.N.J. van Keulen and J.R.H. Ross, Stud. Surf. Sci. Catal., 81 (1994) 285.

[9] S.J. Tauster, S.C. Fung and R.L.J. Garten, J. Am. Chem. Soc, 100 (1978) 170.

[10] S.J. Tauster, Acc. Chem. Res., 20(11) (1987) 389. 